\title{
Lead Hair Level Impact on Mongolian Children with Attention Deficit Hyperactivity Disorder
}

\author{
Bayarsaikhan Amgalan', Avirmed Tovuudorj' ${ }^{1}$ Altangerel Enkhjargal' \\ Lkhagvasuren Nasantsengel ${ }^{3}$, Ganbaatar Erdenetuya ${ }^{1^{*}}$ \\ ${ }^{1}$ Mongolian National University of Medical Sciences, Ulaanbaatar, Mongolia \\ ${ }^{2}$ Academy of Medical Professionals, Ulaanbaatar, Mongolia \\ ${ }^{3}$ National Center of Mental Health, Ulaanbaatar, Mongolia \\ Email: *erdenetuya@mnums.edu.mn
}

How to cite this paper: Amgalan, B., Tovuudorj, A., Enkhjargal, A., Nasantsengel, L. and Erdenetuya, G. (2020) Lead Hair Level Impact on Mongolian Children with Attention Deficit Hyperactivity Disorder. Occupational Diseases and Environmental Medicine, 8, 188-202.

https://doi.org/10.4236/odem.2020.84015

Received: September 24, 2020 Accepted: November 13, 2020

Published: November 16, 2020

Copyright $\odot 2020$ by author(s) and Scientific Research Publishing Inc. This work is licensed under the Creative Commons Attribution International License (CC BY 4.0).

http://creativecommons.org/licenses/by/4.0/

\begin{abstract}
Background: High-prevalence disorders among children are attention-deficit/ hyperactivity disorder (ADHD) and lead exposure. The purpose of this study was to find out the relationship between ADHD symptoms and hair lead levels and neurocognitive function among Mongolian children. Methods: This was the case study to investigate the relationship between hair lead and ADHD in Mongolian school kids. We conducted a pair-matching case-control study with 30 ADHD cases and 30 non ADHD controls for 7 - 12 years of age school children, based on the same age, and sex. Recruitment process was conducted from June 2018 to December 2019. The case and control study children were systematically selected by structured diagnostic interviews, including caregiver interviews based on the Diagnostic and Statistical Manual of Mental Disorders, 4th ed (DSM-IV). Results: The average level of hair lead of the ADHD group was $1.45 \pm 2.93 \mathrm{ppm}$ and the control group's lead level was $0.7 \pm 1.59 \mathrm{ppm}$. We found ADHD-Combined (ADHD-C) patients showed the highest lead levels $(\mathrm{p}<0.05)$. Hair lead levels were positively linked with the severity of ADHD symptoms, negatively linked with the Full-Scale Emotional Intelligence Quotient, but positively correlated with inattention and hyperactivity/impulsivity symptoms $(\mathrm{p}<0.05)$. A statistically significant difference was discovered regarding the lead levels between the study and the control groups with significantly increased risks among boys and children whose mother had preeclampsia during the pregnancy period. Spearman's correlation coefficient showed a notable negative connection between children's hair lead levels with ADHD-Hyperactive (ADHD-H), and EQ (Emotional Quotient) level of children $(-0.329$ and -0.242 , for original and $\log 10$ transformed, $\mathrm{p}<0.001$ ). The lead was linked with vulnerability to ADHD and symptom severity among those school-age children. Conclu-
\end{abstract}


sions: The child hair lead exposure is one of the risk factors of the development of ADHD and decreasing FSIQ (Full Scale Intelligent Quotient) and EQ level of children and linked with susceptibility to ADHD and symptom severity in school-age children.

\section{Keywords}

Hair Lead, Children's ADHD, Risk Factor, EQ, FSIQ

\section{Introduction}

Attention-deficit hyperactivity disorder (ADHD) occurs during the childhood development period which shows signs of reduced attention and hyperactivity/impulsivity. ADHD patients can be divided into three subtypes according to symptoms: inattentive, hyperactive/impulsive, and combined type patients [1]. In a meta-analysis of 179 worldwide studies, the prevalence of ADHD was $31 \%$ in Europe, 25\% in Asia, 26\% in America, and 19\% in other continents. This study was conducted $74 \%$ school-based, whereas $10 \%$ was population-based [2].

Since they measure many features associated with cognitive functions, Wechsler intelligence scales for children (WISC) are among the most frequently used intelligence scales in clinical practice, and in research studies. Wechsler Abbreviated Scale of Intelligence ${ }^{\oplus}$-Second Edition (WASI-II) is an abbreviated cognitive ability test for evaluating the intelligence of individuals aged 6 to 90 years. The WASI-II was developed to provide a quick and accurate estimation of intellectual functioning for screening and reevaluation purposes. It meets the demands for a short and reliable measure of intelligence in clinical, psychoeducational, and research settings [3].

A commonly reported Wechsler profile among school-aged children with ADHD includes lower scores on different indexes. Several published studies have used WISC to evaluate cognitive factors associated with ADHD; in addition, several studies have also used Intelligence Quotient (IQ) or index scores, profile analyses, or subtest assessments 3 - 5. Some studies reported that children diagnosed with ADHD had lower Performance IQ (PIQ) scores (evaluate specific attention tasks) than Verbal IQ (VIQ) scores, as estimated by the Wechsler Intelligence Scale for Children-Revised [4] [5]. Emotional intelligence has to do with the evaluation and expression of emotions experienced by oneself and others, as well as the ability to understand and control such emotions. Bar-On and Parker are two leading researchers in the field of emotional intelligence among children who have sought to develop a concise theory for construct as well as develop valid and reliable measures to test their theory [6].

Initially, the Bar-On Emotional Quotient Inventory (EQ-i) (Bar-On, 1997) was developed to measure emotional intelligence in adults, and more recently, the companion Youth Version was constructed to assess children and adolescents (Bar-On \& Parker, 2000). Both instruments are self-report in format and 
are relatively easy to administer, giving test users a quick and simple method of measuring Bar-On's conception of emotional intelligence [7]. However, children with ADHD also rated themselves slightly lower on average in some areas when it came to putting this EQ knowledge into practice.

Environmental exposures to lead, predominantly from contaminated water or lead paint chips, account for the majority of exposures to children. It is estimated approximately that $3 \%$ of neurodevelopmental disorders and disabilities are caused by exposure to neurotoxins, inducing neuronal damage; intellectual disabilities, ADHD, learning disability, and an autism spectrum disorder. Lead exposure is a major concern for the developing nervous system. In utero and early life exposures to lead have been associated with lower IQ, antisocial and delinquent behaviors, and attention-deficit hyperactivity disorder [8]. Lead is one of the most dangerous environmental pollutants. The WHO (World Health Organization) has identified lead as one of ten chemicals of major public health concern that require action by the Member States in order to protect the health of workers, children, and women of reproductive age [9]. Lead $(\mathrm{Pb})$ is one of the most important models for biomonitoring of exposure, with the blood lead concentration as a predominant choice in practice and epidemiology [10].

Mongolia is a landlocked country in northern Central Asia located between China and Russia; it has a vast grassland steppe, desert, and mountain covering an area of 1,565,000 square kilometers. Mongolia has a surface area of nearly 1.6 million square kilometers with the Gobi desert in the south and mountainous regions in the northern and western parts [11]. Ger districts usually lack access to utilities such as water, electricity, heating, and waste collection and the majority of inhabitants live in gers or in spontaneously built wooden houses with bad insulation [12]. In recent years due to urbanization, coal burning, and increasing numbers of vehicles in Mongolia environmental pollution is getting worse and biomonitoring issues are emerging. Thus, we had conducted a recent study aimed to define hair level of Lead and ADHD-correlation among children aged 7 - 12 years old in Ulaanbaatar, Mongolia.

\section{Materials and Methods}

Sixty Mongolian children of 7 to 12 -year-old, who 30 diagnosed ADHD and 30 healthy controls, residing in Ulaanbaatar city, were chosen in a case-control study. The control group consisted of 30 children with a case group by age, gender, and school year. Almost a half of population of Mongolian population is living in the capital city of Mongolia. Thus the participants' recruitment process was conducted from June, 2018 to December 2019 in capital Ulaanbaatar city of Mongolia. ADHD diagnoses were analyzed according to DSM-IV diagnostic criteria by the psychiatrist for kids at the National Center of Mental Health (NCMH). In total 84 children were diagnosed with ADHD. Upon getting approval from caregivers were agreed to participate in the survey only 30 children's parents. Thus, we also invited same number of children from non-ADHD group. 
We conducted 93 children's caregivers and agreed 60 of them, and we selected 30 children to the non-ADHD group.

Patients with organic diseases and other serious psychiatric disorders, including organic mental disorders, schizophrenia, and other mental disorders; neurodegenerative disorders, traumatic brain injury, or cerebral vascular disease; serious heart, liver, kidney dysfunction, and other major disease history or a history of drug dependency were excluded from the study.

Hair samples of all participants were randomly selected and processed for a panel of mineral analysis by inductively coupled plasma mass spectrometry (ICP-MS). After extensive washing of removing external contamination, hair samples were analyzed by Doctors Data Clinical lab. Hair levels lead was reported in parts per million (ppm) or $\mu \mathrm{g} / \mathrm{g}$. Hair samples were collected by the instruction of the U.S. Doctor's Data Laboratory (https://www.doctorsdata.com/).

The history of hair dyeing was reviewed to exclude possible exogenous bio elements that may be incorporated into hair samples. Scalp hair samples were randomly gathered from approximately ten sites around both sides of posterior parietal eminences and external occipital protuberance. The hair was cut closest to the scalp by stainless steel scissors. Only proximal parts of hair, approximately $2.5 \mathrm{~cm}$ in length, were collected, while the distal parts were thrown away. This ensured that only the recent and uniform period of bio element deposition in each participant's sample was collected. Samples were then packed at room temperature and submitted for laboratory analysis.

The Wechsler Abbreviated Scale of Intelligence (WASI) is a short assessment battery of intelligence for aged 6 - 89. The scale comprises four subtests: Vocabulary, Similarities, Block Design, and Matrix Reasoning. These four subtests yield a verbal intelligence quotient (VIQ), a performance intelligence quotient (PIQ), and a full-scale intelligence quotient (FSIQ). We examined VIQ and PIQ independently in our analyses, given that one PIQ subtest is timed and may be influenced by motor speed, which we hypothesized may be lower in children with ADHD. The subtests are scaled to a $T$-score metric. The WASI-II provides four composite scores: the Verbal Comprehension Index (VCI), the Perceptual Reasoning Index (PRI), the Full-Scale IQ-2 Subtest (FSIQ-2), and the Full-Scale IQ-4 Subtest (FSIQ-4) [13]. For assessment of emotional Intelligence EQ-i: YV Emotional Quotient Inventory: Youth Version [6] (Bar-On \& Parker, 2000; it ad. Sannio Fancello, \& Cianchetti, 2012) was used [14]. Thus, according to the Bar-On model, general intelligence is composed of both cognitive intelligence, measured by IQ, and emotional intelligence measured by EQ. The Bar-On Model of EQ consists of five major dimensions such as intrapersonal, interpersonal, adaptability, stress management, and general mood.

\section{Statistical Analysis}

The most common characteristics of ADHD reported by parents and school teachers were analyzed from their questionnaires to determine specific clinical 
features. Clinical features that were frequently repeated in both questionnaires from parents and teachers were analyzed to reveal specific characteristics of children in Mongolia. The chi-square test was conducted to determine significant differences in the dissemination of the chance to calculate the risk factors after communicating their rate as rates among children with and without the diagnosis of ADHD.

Data Analysis Statistical analyses were conducted using SPSS version 22.0 using the appropriate parametric and nonparametric analysis. Sample characteristics (e.g., age, gender) and their potential effect on the primary hypotheses of interest were assessed with descriptive and correlational analyses. Correlations between hair levels of lead and number of inattention, hyperactivity, and total symptoms were determined by Spearman's correlation. We conducted linear regression analyses to predict the lead level of risk factors for ADHD. The principal component factor analysis was done for defining the main risk factors. Cognitive function and clinical symptoms of selected patients were evaluated, respectively.

\section{Ethical Statements}

The study proposal was approved by the Research Ethics Committee at the Mongolian National University of Medical Sciences (Reg. No. 2018/D-10). All participants were informed about the study and gave written informed consent from the caregivers before the study. Children with ADHD and their parents were free to continue with their allocation in the ADHD group or control group during the study period or withdraw from the study at any time.

\section{Results}

The general characteristics of the child participants are summarized in Table 1 \& Table 2.

Table 1. General socio-economic characteristics of child participants.

\begin{tabular}{lllll}
\hline Indicators & ADHD $(\mathrm{n}=30)$ & Control $(\mathrm{n}=30)$ & $\chi^{2}$ & P value \\
\hline Gender & $24(80.0 \%)$ & $24(80.0 \%)$ & & \\
Boys & $6(20.0 \%)$ & $6(20.0 \%)$ & & \\
Girls & & & & \\
Living condition & $8(26.7 \%)$ & $12(40.0 \%)$ & 1.2 & 0.273 \\
Ger & $22(73.3 \%)$ & $18(60.0 \%)$ & & \\
Apartment & & & & \\
Live with whom & $16(53.3 \%)$ & $23(76.7 \%)$ & & \\
With both parents & $6(20.0 \%)$ & $4(13.3 \%)$ & 3.929 & 0.140 \\
With grand parents & $8(26.7 \%)$ & $3(10.0 \%)$ & & \\
With mother or father & & & & \\
Type of breastfeeding & $25(83.3 \%)$ & $29(96.7 \%)$ & 1.667 & 0.197 \\
Yes & & & & \\
\hline
\end{tabular}




\section{Continued}

\begin{tabular}{lcccc}
\hline No & $5(16.7 \%)$ & $1(3.3 \%)$ & & \\
Birth weight & & & & \\
1500 - 2499 gram & $1(3.4 \%)$ & $3(10.0 \%)$ & & \\
2500 - 4499 gram & $27(93.1 \%)$ & $24(80.0 \%)$ & 2.932 & 0.402 \\
4500 over gram & $1(3.4 \%)$ & $2(6.7 \%)$ & & \\
Unknown & $0(0.0 \%)$ & $1(3.3 \%)$ & & \\
Alcohol usage during the pregnancy period & & & \\
Seldom & $3(10.0 \%)$ & $0(0.0 \%)$ & & \\
Always & $1(3.3 \%)$ & $1(3.3 \%)$ & & \\
Never & $26(86.7 \%)$ & $29(96.7 \%)$ & & \\
Exposed during pregnancy to the secondhand smoke & & & \\
Seldom & $19(63.3 \%)$ & $7(23.3 \%)$ & & \\
Always & $2(6.7 \%)$ & $3(10.0 \%)$ & & \\
Never & $8(26.7 \%)$ & $19(63.3 \%)$ & & \\
Unknown & $1(3.3 \%)$ & $1(3.3 \%)$ & & \\
Pregnant preeclampsia & & & & \\
Yes & $15(53.6 \%)$ & $6(22.2 \%)$ & & \\
No & $13(46.4 \%)$ & $21(77.8 \%)$ & & \\
Pregnancy complications & & & & \\
Yes & $9(32.1 \%)$ & $1(3.7 \%)$ & & \\
No & $19(67.9 \%)$ & $26(96.3 \%)$ & & \\
\hline
\end{tabular}

Table 2. General characteristics of continuous variables of respondents, by both groups.

\begin{tabular}{|c|c|c|c|c|c|c|}
\hline Indicators & Groups & Mean & 95\% Confidence Interval & Median & 95\% Confidence Interval & $\mathrm{P}$-value \\
\hline \multirow{2}{*}{ Age } & ADHD & $9.14 \pm 0.99$ & {$[8.76: 9.46]$} & $9.00 \pm 4.00$ & {$[9.00: 10.00]$} & \multirow{2}{*}{0.343} \\
\hline & Control & $9.34 \pm 0.97$ & {$[8.97: 9.69]$} & $9.00 \pm 4.00$ & {$[9.00: 10.00]$} & \\
\hline \multirow{2}{*}{ BMI } & ADHD & $16.69 \pm 3.09$ & [15.60:17.93] & $15.80 \pm 14.10$ & {$[14.90: 18.10]$} & \multirow{2}{*}{0.882} \\
\hline & Control & $16.86 \pm 3.44$ & {$[15.69: 18.33]$} & $15.90 \pm 14.40$ & {$[14.80: 18.00]$} & \\
\hline \multirow{2}{*}{ Weight } & ADHD & $31.03 \pm 9.21$ & {$[28.15: 35.14]$} & $29.00 \pm 48.00$ & {$[26.50: 32.00]$} & \multirow{2}{*}{0.382} \\
\hline & Control & $32.31 \pm 8.94$ & {$[29.38: 36.24]$} & $30.00 \pm 41.00$ & {$[27.51: 32.00]$} & \\
\hline \multirow{2}{*}{ Height } & ADHD & $135.45 \pm 8.37$ & [132.74:138.70] & $133.00 \pm 39.00$ & [131.00:138.00] & \multirow{2}{*}{0.065} \\
\hline & Control & $137.78 \pm 6.33$ & [135.35:140.19] & $137.00 \pm 25.50$ & [133.75:140.00] & \\
\hline \multirow{2}{*}{ Mother's age } & ADHD & $36.00 \pm 4.83$ & {$[34.45: 37.71]$} & $35.00 \pm 18.00$ & {$[33.00: 38.00]$} & \multirow{2}{*}{0.958} \\
\hline & Control & $36.24 \pm 5.13$ & {$[34.33: 38.20]$} & $36.00 \pm 21.00$ & {$[33.00: 40.00]$} & \\
\hline \multirow{2}{*}{$\begin{array}{l}\text { Number of family } \\
\text { members }\end{array}$} & ADHD & $4.48 \pm 0.69$ & {$[4.22: 4.72]$} & $5.00 \pm 2.00$ & {$[4.00: 5.00]$} & \multirow{2}{*}{0.677} \\
\hline & Control & $4.52 \pm 0.87$ & {$[4.17: 4.81]$} & $5.00 \pm 3.00$ & {$[5.00: 5.00]$} & \\
\hline \multirow{2}{*}{ EQ score } & ADHD & $52.28 \pm 6.17$ & [50.00:54.45] & $52.00 \pm 28.00$ & {$[48.00: 56.00]$} & \multirow{2}{*}{$<0.001$} \\
\hline & Control & $59.24 \pm 5.68$ & [57.22:61.39] & $58.00 \pm 19.00$ & [56.00:62.00] & \\
\hline \multirow{2}{*}{ FSIQ } & ADHD & $85.66 \pm 16.81$ & [79.80:92.27] & $80.00 \pm 61.00$ & [75.00:93.97] & \multirow{2}{*}{$<0.001$} \\
\hline & Control & $110.17 \pm 20.40$ & {$[102.52: 118.24]$} & $117.00 \pm 76.00$ & [99.00:123.00] & \\
\hline \multirow{2}{*}{$\mathrm{Pb}$ level } & ADHD & $1.39 \pm 0.76$ & {$[1.12: 1.67]$} & $1.50 \pm 2.93$ & {$[1.06: 1.70]$} & \multirow{2}{*}{0.003} \\
\hline & Control & $0.81 \pm 0.48$ & [0.64:1.00] & $0.70 \pm 1.59$ & [0.49:0.86] & \\
\hline
\end{tabular}


In both groups, gender, living condition, birth weight of children participants was the same. $26.7 \%$ of the ADHD group, $40.0 \%$ of the control group children lived in ger area. $53.3 \%$ of ADHD and $76.7 \%$ of the control group children lived with both parents.

The characteristics of respondents of both groups on birth weight, breastfeeding, and alcohol usage during the pregnant period were significantly the same. However, mother's exposure during the pregnancy period, pregnant preeclampsia, any pregnancy complications were significantly high among children with ADHD (Table 1).

According to the ADHD types, $20.0 \%$ of the ADHD group of children diagnosed as an ADHD-I, 21.7\% of them diagnosed as an ADHD-H and $8.3 \%$ of them had an ADHD-C. The median age of both groups of children was $9.00 \pm$ 4.00 .

There were not observed a significant difference between children of both groups on their BMI $(\mathrm{ADHD}=15.80 \pm 14.10$, control $=15.90 \pm 14.40)$, weight $(\mathrm{ADHD}=29.00 \pm 48.00$, control $=30.00 \pm 41.00)$, height $(\mathrm{ADHD}=133.00 \pm$ 39.00 , control $=137.00 \pm 25.50)$, mother's age $(\mathrm{ADHD}=35.00 \pm 18.00$, control $=$ $36.00 \pm 21.00$ ), and numbers of a family member ( $\mathrm{ADHD}=5.00 \pm 2.00$, control $=5.00 \pm 3.00$ ).

The median of EQ score and FSIQ score of children of the ADHD group (EQ $=52.00 \pm 28.00$, FSIQ $=80.00 \pm 61.00$ ) were significantly lower than the control group $(\mathrm{EQ}=58.00 \pm 19.00$, FSIQ $=117.00 \pm 76.00)$. Despite the fact, the hair lead level of children of the ADHD group was 2.14 times higher than the control group (Table 2).

The detailed hair level of lead was shown in Table 3. The hair lead level was significantly high among ADHD group's boys $(\mathrm{p}=0.025), 9(\mathrm{p}=0.043)$ and 10 years old children $(p=0.034)$, normal weighted child $(p=0.02)$, a child who lives in an apartment $(\mathrm{p}=0.03)$, a child who had a mother of higher education $(\mathrm{p}=0.01)$, a child living with dual-parents $(0.028)$, and child whose mother had preeclampsia during a pregnant period $(\mathrm{p}=0.033)$ had significantly higher hair lead level by 1.6 - 2.9 times than the control group.

Table 3. The average concentration of lead $(\mathrm{Pb})$ in hair.

\begin{tabular}{|c|c|c|c|c|c|}
\hline \multirow{2}{*}{ Indicators } & \multicolumn{2}{|l|}{$\mathrm{ADHD}$} & \multicolumn{2}{|l|}{ Control } & \multirow{2}{*}{-P-value } \\
\hline & Mean \pm SD & Median \pm IQR & Mean \pm SD & Median $\pm \mathrm{IQR}$ & \\
\hline \multicolumn{6}{|l|}{ Gender } \\
\hline Boys & $1.345 \pm 0.806$ & $1.390 \pm 2.930$ & $0.803 \pm 0.451$ & $0.700 \pm 1.520$ & 0.025 \\
\hline Girls & $1.577 \pm 0.467$ & $1.450 \pm 1.370$ & $0.867 \pm 0.604$ & $0.710 \pm 1.430$ & 0.135 \\
\hline \multicolumn{6}{|l|}{ Age } \\
\hline 8 years & $1.274 \pm 0.692$ & $1.230 \pm 2.030$ & $0.998 \pm 0.593$ & $0.930 \pm 1.360$ & 0.476 \\
\hline 9 years & $1.675 \pm 0.882$ & $1.680 \pm 2.720$ & $0.871 \pm 0.521$ & $0.700 \pm 1.520$ & 0.043 \\
\hline 10 years & $1.233 \pm 0.654$ & $1.435 \pm 2.040$ & $0.707 \pm 0.396$ & $0.625 \pm 1.390$ & 0.034 \\
\hline
\end{tabular}




\section{Continued}

\section{BMI}

Underweight

$1.257 \pm 0.776$

$1.400 \pm 2.290 \quad 1.223 \pm 0.422 \quad 1.360 \pm 0.810$

0.864

Normal

$1.623 \pm 0.773$

$1.585 \pm 2.740 \quad 0.762 \pm 0.462 \quad 0.680 \pm 1.590$

0.02

Overweight

$1.159 \pm 0.712$

$0.920 \pm 2.140 \quad 1.015 \pm 0.827 \quad 1.015 \pm 1.170$

0.889

Obese

1.690

$1.690 \pm 0.000 \quad 0.667 \pm 0.388 \quad 0.550 \pm 0.750$

0.5

Living conditions

Apartment

$1.534 \pm 0.657$

$1.450 \pm 1.950 \quad 0.668 \pm 0.354 \quad 0.520 \pm 1.210$

0.03

Ger area

$1.340 \pm 0.788$

$1.495 \pm 2.930 \quad 0.914 \pm .526 \quad 0.745 \pm 1.59$

0.07

Mother's education level

Bachelor and high

$1.229 \pm 0.462$

$1.365 \pm 1.160 \quad 0.619 \pm 0.407 \quad 0.470 \pm 1.360$

0.01

Not completed secondary $1.645 \pm 0.835$

$1.900 \pm 2.210 \quad 1.248 \pm 0.467 \quad 1.350 \pm 1.120$

0.263

Secondary

$1.289 \pm 0.940$

$1.150 \pm 2.930 \quad 0.868 \pm 0.446 \quad 0.745 \pm 1.390$

0.481

\section{Family structure}

Dual-parents

$1.316 \pm 0.732$

$1.300 \pm 2.400 \quad 0.787 \pm 0.446 \quad 0.700 \pm 1.430$

0.028

Grandparents

$1.420 \pm 0.625$

$1.560 \pm 1.830 \quad 0.910 \pm 0.573 \quad 0.910 \pm 1.340$

0.171

Single mother or father

$1.520 \pm 0.930$

$1.550 \pm 2.670 \quad 0.910 \pm 0.739 \quad 0.550 \pm 1.340$

0.376

Pregnant preeclampsia

Yes

$1.452 \pm 0.833$

No

$1.322 \pm 0.664$

Pregnancy complications

Yes

$1.749 \pm 0.723$

$1.620 \pm 2.480 \quad 0.930$

$0.930 \pm 0.000$

0.400

No

$1.238 \pm 0.723$

Had difficulties with learning at the class

\begin{tabular}{llllll} 
Yes & $1.334 \pm 0.804$ & $1.230 \pm 2.930$ & $0.839 \pm 0.577$ & $0.685 \pm 1.590$ & 0.226 \\
No & $1.596 \pm 0.692$ & $1.740 \pm 1.920$ & $0.772 \pm 0.431$ & $0.700 \pm 1.360$ & 0.023 \\
Unknown & $0.450 \pm 0.184$ & $0.450 \pm 0.260$ & $0.420 \pm 0.154$ & $0.420 \pm 0.000$ & 0.109 \\
Family pressures & & & & & \\
Yes & $1.414 \pm 0.933$ & $1.230 \pm 2.740$ & $0.755 \pm 0.595$ & $0.590 \pm 1.360$ & 0.286 \\
No & $1.374 \pm 0.694$ & $1.620 \pm 2.300$ & $0.852 \pm 0.428$ & $0.700 \pm 1.360$ & 0.004 \\
Unknown & $1.395 \pm 0.525$ & $1.460 \pm 1.260$ & $0.753 \pm 0.592$ & $0.430 \pm 1.590$ & 0.636 \\
Academic performance & & & & & \\
A & $1.285 \pm 0.217$ & $1.260 \pm 0.480$ & $0.837 \pm 0.485$ & $0.705 \pm 1.590$ & 0.091 \\
B & $1.266 \pm 0.835$ & $1.400 \pm 2.300$ & $1.061 \pm 0.446$ & $1.025 \pm 1.130$ & 0.636 \\
C & $1.596 \pm 0.790$ & $1.595 \pm 2.480$ & $0.666 \pm 0.473$ & $0.555 \pm 1.590$ & 0.004 \\
D & $1.650 \pm 0.256$ & $1.650 \pm 0.001$ & $0.935 \pm 0.484$ & $0.925 \pm 1.210$ & 0.286 \\
\hline
\end{tabular}

The average level of hair lead (ppm) of the ADHD group was $1.45 \pm 2.93 \mathrm{ppm}$ and the control group's lead level was $0.7 \pm 1.59 \mathrm{ppm}$. The highest hair level of 
lead was determined in children who had ADHD-C. Besides, when hair lead is high then more likely the children's academic performance is low and they have difficulties at school (Figure 1).

Linear regression analysis confirmed that there is a substantial negative relationship with children's hair lead by FSIQ and EQ and a positive relationship between hair lead with 3 types of ADHD when adjusted for the confounders. In general, $5.8 \%$ - $15.3 \%$ of selected indicators displayed by Table 4 are explained by the hair lead level. The highest regression was defined to the EQ (15.3\%) and the lowest was ADHD-I (Table 4).

The factor analysis was conducted to define the main factors for developing ADHD among children. The three main factors are for factor 1 was children's age, BMI, and mother's age. Another main factor by factor 2 was hair Pb level, age of children and mother's age. While the main 3 factors of third option were mother's age, FSIQ, and BMI). In general aspect, the main factors that child gets ADHD are hair lead level, and age of child and mother (Table 5).

Spearman's correlation coefficient displays a significant negative relationship between children's hair lead levels with ADHD-H, and EQ level of children $(-0.329$ and -0.242 , for original and $\log 10$ transformed, $\mathrm{p}<0.001)$ (Figure 2$)$.

Table 4. Linear regression analysis model of hair $\mathrm{Pb}$ with ADHD (I, H, C), IQ, and EQ.

\begin{tabular}{llll}
\hline Dependent variables & Equation of regression & P-value & Adjusted R \\
\hline ADHD-I & $4.776+2.151 \times \mathrm{Pb} \mathrm{ppm}$ & 0.036 & 0.058 \\
ADHD-H & $3.929+3.145 \times \mathrm{Pb} \mathrm{ppm}$ & 0.04 & 0.123 \\
ADHD-C & $0.167+0.378 \times \mathrm{Pb} \mathrm{ppm}$ & 0.01 & 0.147 \\
FSIQ & $108.384-10.347 \times \mathrm{Pb} \mathrm{ppm}$ & 0.014 & 0.084 \\
EQ & $105.278-7.743 \times \mathrm{Pb} \mathrm{ppm}$ & 0.01 & 0.153 \\
\hline
\end{tabular}

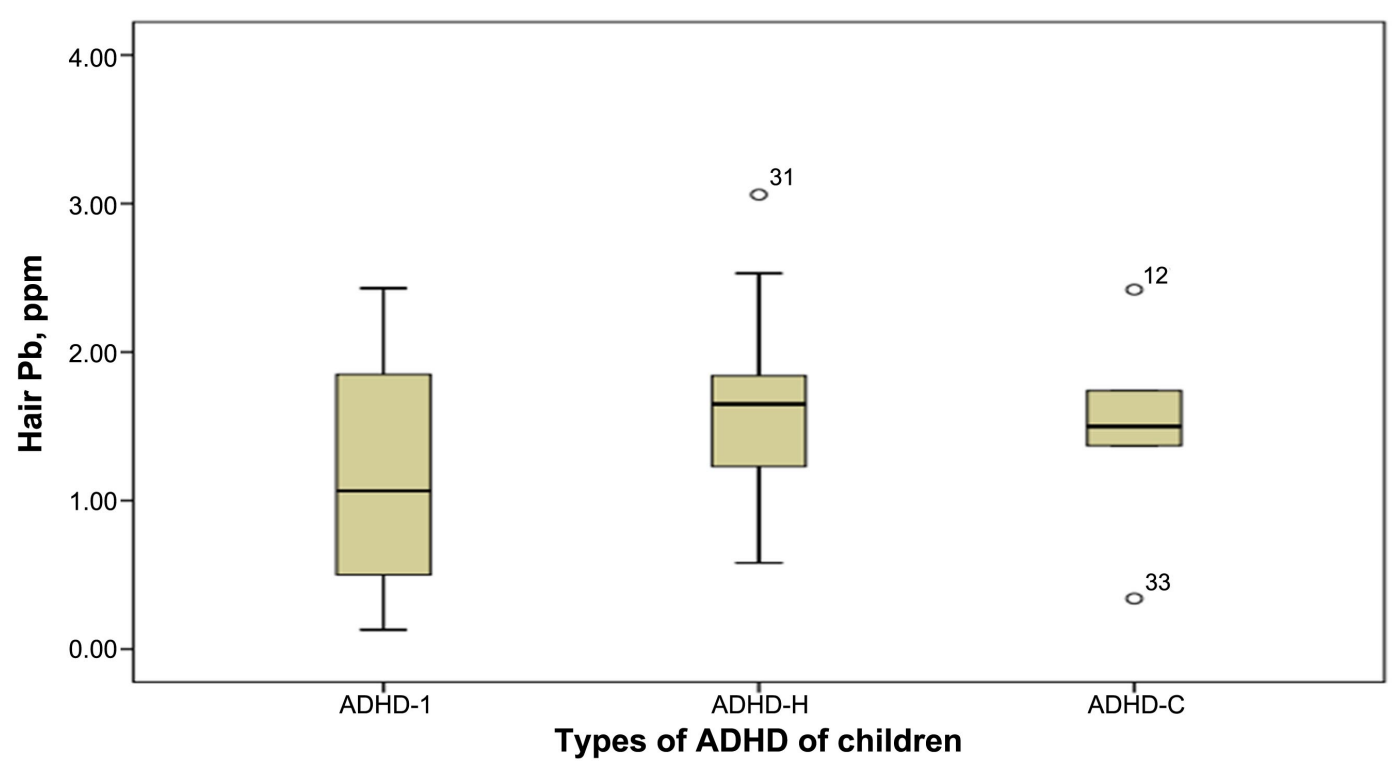

Figure 1. Hair lead $(\mathrm{Pb})$ level by ADHD types of children. 
Table 5. Principal component factor analysis of ADHD.

\begin{tabular}{llll}
\hline & \multicolumn{2}{l}{ Component } & \\
\cline { 2 - 4 } & Model 1 & Model 2 & Model 3 \\
\hline Age & 0.337 & 0.560 & 0.356 \\
Mother's age & 0.279 & 0.336 & 0.777 \\
BMI & 0.316 & 0.543 & 0.439 \\
Hair Pb level & 0.009 & 0.610 & 0.047 \\
EQ & 0.940 & 0.099 & 0.017 \\
FSIQ & 0.681 & 0.520 & 0.369 \\
\hline
\end{tabular}

Extraction Method: Principal Component Analysis. a. 3 components extracted.

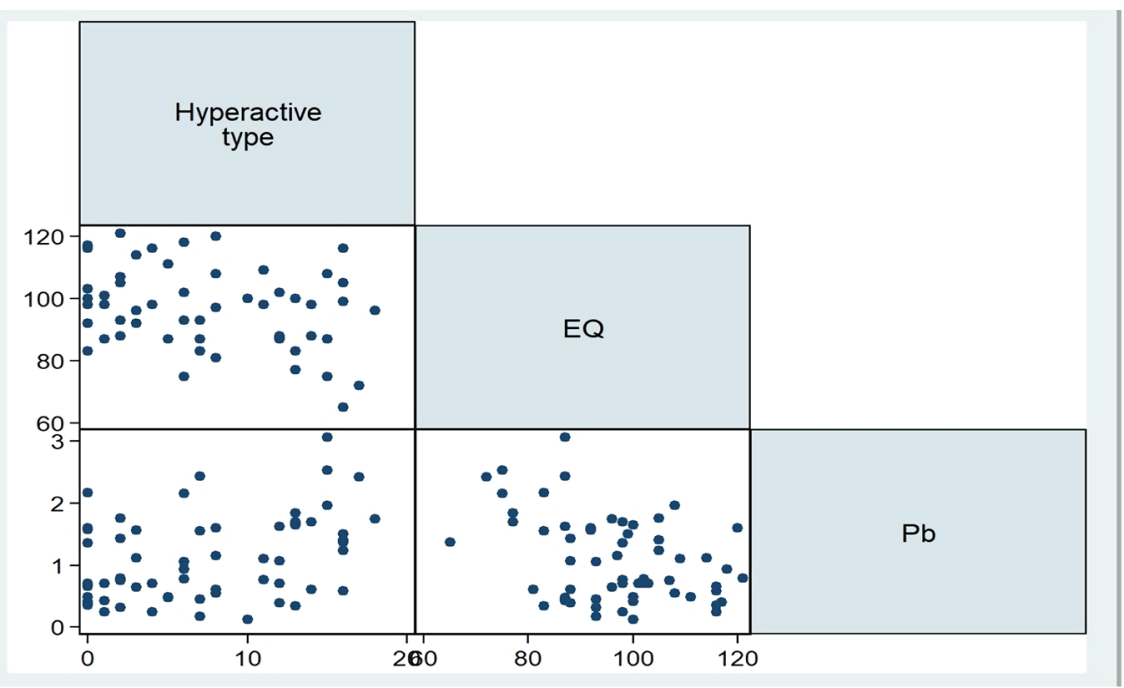

Figure 2. Spearman correlation between hair levels of lead $(\mathrm{Pb})$ with children ADHD-H (hyperactive type) and EQ.

\section{Discussions}

We examined the consequences of hair lead in ADHD cases and non-ADHD controls with adjustment for many other known risk factors among children 7 12 years of age in Mongolia. Mother's exposure during the pregnancy period which was exposed to secondhand smoke, preeclampsia, any pregnancy complications were positive high-risk factors. This is consistent with previous work indicating that low maternal education, low socioeconomic status, prenatal smoking, prenatal illicit drug use, maternal depression, and single parenthood are important adverse factors for ADHD [15] [16] [17].

We discovered that ADHD cases were more likely to have been exposed to lead. In our study, the children with hair lead high level had 2.14 fold higher risks for ADHD. Lead may play important roles in the etiology of ADHD. Recently, Braun et al. analyzed data from a U.S. population-based sample and concluded that prenatal tobacco exposure and environmental lead are risk factors for ADHD; they found 4.1-fold increased odds of ADHD with increased blood 
lead levels [18].

Awaga et al. had conducted a case-control study on lead exposure among Egyptian children. The lead level among ADHD children was significantly higher than control $(20.88 \pm 7.47 \mathrm{ug} / \mathrm{dl}$ versus $16.13 \pm 7.91 \mathrm{ug} / \mathrm{dl})$. While, there is no significant difference between lead level and degree of symptoms among ADHD children. There is a notable connection with ADHD in the examined sample of children and exposure to lead especially through water decontamination containing lead [19]. The lead level is significant for reflecting exposure to lead. Based on our survey findings of hair lead is a risk factor of child ADHD.

Choi et al. was investigated the blood lead level and parental marital status that might affect the development of attention-deficit/hyperactivity disorder (ADHD) symptoms in school-aged children. The participants in the survey were elementary school children, and they were followed up biennially. The participants' parents or caregivers were given a questionnaire to fill out containing an ADHD rating scale. Among 2967 who were not suspected to have ADHD at baseline survey, 2195 children who took follow-up tests for ADHD were evaluated. The RR was 3.567 (95\% CI 1.595 - 7.980) in children with relatively high blood lead levels $(42.17 \mu \mathrm{g} / \mathrm{dL})$ from single-parent families, compared with low blood lead and a two-parent family. The ADHD risk in association with blood lead level was altered by family status [20]. Similar patterns were defined in this study.

A study was conducted on hair samples of children with ADHD and revealed that children's hair lead concentrations ranged from less than one to $11.3 \mathrm{ppm}$ $(\mu \mathrm{g} / \mathrm{g})$ with an observed notably striking relation between ADHD and hair lead levels. Children with a blood lead level $\geq 5 \mu \mathrm{g} / \mathrm{dl}$ doubled the risk of developing ADHD whereas, in inorganic arsenic, a greater risk is observed only when urinary inorganic arsenic concentration is in the highest quintile [21].

Previous studies have reported that environmental toxicants, especially lead and mercury, contribute to the risk of ADHD. A meta-analysis was conducted by Goodlad et al. discovered that lead exposure was associated not only with inattention and hyperactivity/impulsivity symptoms but also intelligence among children and adolescents, with a small effect size $(r=0.13-0.16)$ [22]. Specifically, lower scores were found on self-rated performance when interacting with others, as well as adapting to new environments. Both of these skills are more common areas of difficulty for children with ADHD [23]. Children with ADHD also reported comparable performance abilities on the trait-based total EQ-I score, as well as on the Intrapersonal and Stress Management scales. However, they scored significantly lower on the Interpersonal and Adaptability Scales, as well as on the Positive Impression Scale [24]. In our study, it was also the same, if a child had a higher level of hair lead then FSIQ, and the EQ score of the child was low. Some studies documented varying behavioral effects of lead exposure among children [15] [20]. In this regard, it is noteworthy that concurrent rather than earlier blood lead levels have shown the strongest association with IQ in school-age children [25] [26] [27]. 
Based on the results of observational studies findings, there is an association between lead and ADHD and that even low levels of lead raise the risk. However, there is still a lack of longitudinal studies about the relationship between lead exposure and the development of ADHD. Given the potential importance for public health, further research including the entire potential risk factors for ADHD in children must be encouraged [28].

Generally, exposure to neurotoxicants earlier in life has a more critical effect on the brain; this is also the case for many other environmental chemicals [29] [30]. Therefore, regarding the reported correlations between concurrent lead exposure and child IQ, an alternative hypothesis may need to be taken into account when inferring the direction of causality. For example, a child who is experiencing symptoms of ADHD is perhaps at a higher chance of undergoing greater amounts of environmental lead exposure [31]. We had defined a direct correlation between hair lead and ADHD among children.

In Mongolia, a few researchers have conducted studies on lead and child health. In 2019, Erdenechimeg et al. had defined the mean blood lead level of children in the two cities of Mongolia was found to be $3.8 \pm 2.6 \mu \mathrm{g} / \mathrm{dL}$ (range: < $1.5-17.2 \mu \mathrm{g} / \mathrm{dL}$ ) and $27.8 \%$ of the children had blood lead levels $\geq 5 \mu \mathrm{g} / \mathrm{dL}$. The average blood lead level of children in Erdenet (a mining center) was significantly higher than that for children in Darkhan, and there was a statistically significant difference between the average blood lead level of children who live in ger districts $(4.2 \pm 2.8 \mu \mathrm{g} / \mathrm{dL})$ compared to those of children living in city apartments $(3.2 \pm 2.4 \mu \mathrm{g} / \mathrm{dL})$. Despite the low values, blood lead levels were significantly associated with several effects on the spectrum of behavioral disorders, specifically with the scores for hyperactivity, conduct disorder, and prosocial behavior [32]. Based on our survey, children who live in ger districts have higher levels of hair lead compared with children who live in apartments.

While Tuul et al. have been defined that the hair lead level of children who had allergic rhinitis was higher than the healthy children and the hair lead level of boys was 1.6 times higher than the girls [33]. Regarding our survey, the hair levels of the boy's lead in the ADHD group were significantly higher than the control group. While no significant difference was observed among girls of both groups.

Moreover, the blood test conducted among Ulaanbaatar children to detect the content of lead, which has a strong negative impact on all the organs, in particular the nerves, kidneys, blood generation, and reproductive system and delays growth of children, revealed that the average content of lead is $16 \mathrm{mgr} / \mathrm{dl}$, which is high enough to affect children's health. The main sources of lead in the air of Ulaanbaatar are the smoke of automobiles that use lead-containing petroleum and households burning raw coal for heating [34].

\section{Conclusion}

In conclusion, our findings revealed that executive function patterns are different in children with ADHD compared to normal children and confirmed that 
ADHD subtypes are different in terms of perseveration and response inhibition domains; ADHD-C type showed more deficits in perseveration and response inhibition. The child hair lead exposure is one of the risk factors of the development of ADHD and reducing FSIQ and EQ level of children and is associated with susceptibility to ADHD and symptom severity in school-age children.

\section{Limitations}

This study suffers some limitations. First, in this study, we did not compare behavioral differences between children with ADHD and other neurodevelopmental disorders. Another limitation is that the cognitive processes investigated were not supported by the other neuropsychological tests. The third limitation was the special use of retrospective measures such as information of the perinatal period, socio-economic, and childhood behavior.

\section{Conflicts of Interest}

The authors declare no conflicts of interest regarding the publication of this paper.

\section{References}

[1] Nelson, R.M. (2016) Textbook of Pediatrics. Vol. 2. Elsevier, Amsterdam.

[2] Thomas, R., Sanders, S., Doust, J., Beller, E. and Glasziou, P. (2015) Prevalence of Attention-Deficit/Hyperactivity Disorder: A Systematic Review and Meta-Analysis. Pediatrics, 135, e994-e1001. https://doi.org/10.1542/peds.2014-3482

[3] Gomez, R., Vance, A. and Watson, S.D. (2016) Structure of the Wechsler Intelligence Scale for Children-Fourth Edition in a Group of Children with ADHD. Frontiers in Psychology, 7, 737. https://doi.org/10.3389/fpsyg.2016.00737

[4] Celik, C., Erden, G., Özmen, S. and Tural Hesapçioğlu, S. (2017) Comparing Two Editions of Wechsler Intelligence Scales and Assessing Reading Skills in Children with Attention Deficit and Hyperactivity Disorder. Turkish Journal of Psychiatry, 28, 1. https://doi.org/10.5080/u13637

[5] Agnew-Blais, J.C., Polanczyk, G.V., Danese, A., Wertz, J., Moffitt, T.E. and Arseneault, L. (2019) Are Changes in ADHD Course Reflected in Differences in IQ and Executive Functioning from Childhood to Young Adulthood? Psychological Medicine, 1-10. https://doi.org/10.1017/S0033291719003015

[6] Bar-On, R. (2006) The Bar-On Model of Emotional-Social Intelligence (ESI). Psicothema, 18, 13-25.

[7] Bar-On, R. and Parker, J.D.A. (2000) Bar-On Emotional Quotient Inventory: Youth Version. Multi-Health System Incorporated, Toronto.

[8] von Ehrenstein, O.S., Ling, C., Cui, X., et al. (2019) Prenatal and Infant Exposure to Ambient Pesticides and Autism Spectrum Disorder in Children: Population Based Case-Control Study. BMJ, 364, 1962. https://doi.org/10.1136/bmj.1962

[9] World Health Organization International Lead Poisoning Prevention Awareness Campaign. http://www.who.int/ipcs/lead_campaign/QandA_lead_2017_en.pdf

[10] Bergdahl, I.A. and Skerfving, S. (2008) Biomonitoring of Lead Exposure-Alternatives to Blood. Journal of Toxicology and Environmental Health, Part A, 71, 1235-1243. https://doi.org/10.1080/15287390802209525 
[11] Sternberg, T., Rueff, H. and Middleton, N. (2015) Contraction of the Gobi Desert, 2000-2012. Remote Sensing, 7, 1346-1358. https://doi.org/10.3390/rs70201346

[12] U. TT (1969) Physical Geography of Mongolia. Ulaanbaatar.

[13] Canivez, G.L., Watkins, M.W. and Dombrowski, S.C. (2017) Structural Validity of the Wechsler Intelligence Scale for Children-Fifth Edition: Confirmatory Factor Analyses with the 16 Primary and Secondary Subtests. Psychological Assessment, 29, 458. https://doi.org/10.1037/pas0000358

[14] Bar-On, R. and Parker, J.D.A. (2000) The Handbook of Emotional Intelligence: Theory, Development, Assessment, and Application at Home, School, and in the Workplace. Jossey-Bass Inc., San Francisco.

[15] Nigg, J.T., Knottnerus, G.M., Martel, M.M., et al. (2008) Low Blood Lead Levels Associated with Clinically Diagnosed Attention-Deficit/Hyperactivity Disorder and Mediated by Weak Cognitive Control. Biological Psychiatry, 63, 325-331. https://doi.org/10.1016/j.biopsych.2007.07.013

[16] Motlagh, M.G., Katsovich, L., Thompson, N., et al. (2010) Severe Psychosocial Stress and Heavy Cigarette Smoking during Pregnancy: An Examination of the Preand Perinatal Risk Factors Associated with ADHD and Tourette Syndrome. European Child \& Adolescent Psychiatry, 19, 755-764.

https://doi.org/10.1007/s00787-010-0115-7

[17] Tole, F., Kopf, J., Schröter, K., et al. (2019) The Role of Pre-, Peri-, and Postnatal Risk Factors in Bipolar Disorder and Adult ADHD. Journal of Neural Transmission, 126, 1117-1126. https://doi.org/10.1007/s00702-019-01983-4

[18] Abramovitch, A., Anholt, G., Raveh-Gottfried, S., Hamo, N. and Abramowitz, J.S. (2018) Meta-Analysis of Intelligence Quotient (IQ) in Obsessive-Compulsive Disorder. Neuropsychology Review, 28, 111-120. https://doi.org/10.1007/s11065-017-9358-0

[19] Awaga, M., Abdel Hamed, N., Hammad, E.E.D.M., Mohammed, R.H. and Yassa, H. (2020) Lead as a Risk Factor for Attention Deficit Hyperactivity Disorder (ADHD) in Children. Zagazig Journal of Forensic Medicine, 18, 21-33. https://doi.org/10.21608/zjfm.2019.14504.1033

[20] Choi, W.-J., Kwon, H.-J., Lim, M.H., Lim, J.-A. and Ha, M. (2016) Blood Lead, Parental Marital Status and the Risk of Attention-Deficit/Hyperactivity Disorder in Elementary School Children: A Longitudinal Study. Psychiatry Research, 236, 42-46. https://doi.org/10.1016/j.psychres.2016.01.002

[21] Muñoz, M.P., Rubilar, P., Valdés, M., et al. (2020) Attention Deficit Hyperactivity Disorder and Its Association with Heavy Metals in Children from Northern Chile. International Journal of Hygiene and Environmental Health, 226, Article ID: 113483. https://doi.org/10.1016/j.ijheh.2020.113483

[22] Huang, S., Hu, H., Sánchez, B.N., et al. (2016) Childhood Blood Lead Levels and Symptoms of Attention Deficit Hyperactivity Disorder (ADHD): A Cross-Sectional Study of Mexican Children. Environmental Health Perspectives, 124, 868-874. https://doi.org/10.1289/ehp.1510067

[23] Antshel, K.M., Hier, B.O. and Barkley, R.A. (2014) Executive Functioning Theory and ADHD. In: Handbook of Executive Functioning, Springer, Berlin, 107-120. https://doi.org/10.1007/978-1-4614-8106-5_7

[24] Climie, E.A., Saklofske, D.H., Mastoras, S.M. and Schwean, V.L. (2019) Trait and Ability Emotional Intelligence in Children with ADHD. Journal of Attention Disorders, 23, 1667-1674. https://doi.org/10.1177/1087054717702216

[25] Lam, J., Lanphear, B.P., Bellinger, D., et al. (2017) Developmental PBDE Exposure 
and IQ/ADHD in Childhood: A Systematic Review and Meta-Analysis. Environmental Health Perspectives, 125, Article ID: 086001.

https://doi.org/10.1289/EHP1632

[26] Lam, J., Bellinger, D., Lanphear, B., et al. (2016) Exploring the Association between Developmental PBDE Exposure and IQ/ADHD Effects: Application of the Navigation Guide Systematic Review Methodology. ISEE Conference Abstracts, Rome, 1-4 September 2016, Abstract Number 3-122. https://doi.org/10.1289/isee.2016.4737

[27] Ma, M., Liang, X., Cheng, S., et al. (2018) Integrating Genome-Wide Association Study, Chromosomal Enhancer Maps and Element-Gene Interaction Networks Detected Brain Regions Related Associations between Elements and ADHD/IQ. Behavioural Brain Research, 353, 137-142. https://doi.org/10.1016/j.bbr.2018.07.008

[28] Donzelli, G., Carducci, A., Llopis-Gonzalez, A., et al. (2019) The Association between Lead and Attention-Deficit/Hyperactivity Disorder: A Systematic Review. International Journal of Environmental Research and Public Health, 16, 382. https://doi.org/10.3390/ijerph16030382

[29] Fruh, V., Rifas-Shiman, S.L., Amarasiriwardena, C., et al. (2019) Prenatal Lead Exposure and Childhood Executive Function and Behavioral Difficulties in Project Viva. NeuroToxicology, 75, 105-115. https://doi.org/10.1016/j.neuro.2019.09.006

[30] Lee, M.-J., Chou, M.-C., Chou, W.-J., et al. (2018) Heavy Metals' Effect on Susceptibility to Attention-Deficit/Hyperactivity Disorder: Implication of Lead, Cadmium, and Antimony. International Journal of Environmental Research and Public Health, 15, 1221. https://doi.org/10.3390/ijerph15061221

[31] Goodlad, J.K., Marcus, D.K. and Fulton, J.J. (2013) Lead and Attention-Deficit/Hyperactivity Disorder (ADHD) Symptoms: A Meta-Analysis. Clinical Psychology Review, 33, 417-425. https://doi.org/10.1016/j.cpr.2013.01.009

[32] Erdenebayar, E., Dos Santos, K., Edwards, A., Dugersuren, N.-O., Ochir, C. and Nriagu, J. (2019) Environmental Injustice and Childhood Lead Exposure in Peri-Urban (Ger) Areas of Darkhan and Erdenet, Mongolia. BMC Public Health, 19, 163. https://doi.org/10.1186/s12889-019-6486-X

[33] Tuul, B.A.K., Khishigmaa, B., Ariunjargal, M., Serjmyadag, Kh. and Enkhzol, M. (2018) The Comparative Study Result of Child Hair Zn and Se Level on Allergric Dermatitis with Relatively Health Child. Mongolian Journal of Pediatrics, 2, 80-89.

[34] Baigal, O.B.B., Enkhtsetseg, Sh., et al. (2006) The Correlation between Children's Neurological Symptoms with Blood Lead Level in Ulaanbaatar City. Journal of Mongolian Medical Sciences, 1, 28-33. 